\title{
SISTEM INFORMASI PENGADAAN BARANG DAN JASA KONSTRUKSI GUNA MONITORING PERSEDIAAN PADA PT. SAKA JAGAD PRATAMA
}

\author{
Wulandari ${ }^{1)}$,Angga Aditya Wicaksono ${ }^{2)}$, Bawono Bayu Aji Salim ${ }^{3)}$ \\ ${ }^{\left.1-3^{*}\right)}$ Program Studi Sistem Informasi, Fakultas Teknologi Informasi, \\ Universitas Budi Luhur \\ Jl. Ciledug Raya, Petukangan Utara, Jakarta Selatan 12260
}

\begin{abstract}
Abstrak : Perkembangan teknologi yang semakin pesat peran tenaga listrik sangatlah penting bagi segala bidang, PT.Saka Jagad Pratama adalah mitra PLN yang menyediakan komponen listrik. Saat ini kegiatan pencatatan pengadaan barang dan jasa yang ada pada PT Saka Jagad Pratama masih dilakukan menggunakan excel dan tulis tangan, sehingga dalam pencatatan stok barang sering terjadi kesalahan dan data yang disajikan tidak akurat dan penyajian laporan memakan waktu lama dikarenakan data terselip, hilang akibat human error. Untuk itu perlu dibuatkan sebuah sistem yang dapat membantu dalam kegiatan pencatatan pengadaan barang agar informasi stok barang lebih akurat. Metode yang digunakan dalam penelitian ini adalah prototype, untuk memodelkan sistem menggunakan Unified Modeling Language(UML), Bahasa pemrograman yang digunakan Java dan database Mysql, dan untuk pengujian penulis menggunakan Blackbox testing. Pada akhir penelitian ini menghasilkan sebuah produk sistem informasi pengadaan barang berbasis desktop yang diharapkan dapat meminimalisir kesalahan stok barang, mempermudah dalam penyajian laporan dan mempermudah dalam monitoring ketersediaan barang.
\end{abstract}

Kata Kunci : Sistem Informasi, Pengadaan Barang, Monitoring, Persediaan

Abstract : The rapid development of technology, the role of electric power is very important for all fields, PT. Saka Jagad Pratama is a PLN partner that provides electrical components. Currently, the activities of recording the procurement of goods at PT Saka Jagad Pratama are still carried out using excel and handwritten, so that in recording the stock of goods there are often errors and the data presented is not accurate and the presentation of reports takes a long time because the data is tucked away, lost due to human error. For this reason, it is necessary to create a system that can assist in recording procurement activities so that inventory information is more accurate. The method used in this study is a prototype, to model the system using the Unified Modeling Language (UML), the programming language used is Java and the Mysql database, and for testing the author uses Blackbox testing. At the end of this research they produce a desktop-based procurement information system product which is expected to minimize stock information errors and simplify the presentation of reports.

Keywords: Information System, Procurement of Goods, Monitoring, Inventory

\section{PENDAHULUAN}

Peranan Tenaga listrik dalam kehidupan sehari-hari sangatlah penting dalam segala bidang, contohnya dalam bidang industri, pendidikan, kesehatan dll. Tenaga listrik juga termasuk salah satu sumber utama dari perkembangan teknologi yang sangat berkembang pesat di jaman ini. Oleh karena itu, tenaga listrik harus menjalankan fungsinya dengan baik untuk 
membantu kegiatan dan kebutuhan seharihari masyarakat.

PT.Saka Jagad Pratama selaku mitra atau anak cabang dari PT.PLN adalah institusi yang bergerak dalam bidang konstruksi dan ketenagalistrikan yang masih menggunakan excel dan tulis tangan. Saat ini hampir semua bidang usaha, jasa, instansi, institusi dan organisasi sudah beralih menggunakan teknologi, peralihan kegiatan administrasi yang semula masih manual menjadi sangatlah penting, selain dapat membantu meringankan pekerjaan(Wulandari 2020)(Fajarita et al. 2018).

Dalam kegiatan maintenance alat-alat konstruksi dan ketenagalistrikan PT.Saka Jagad Pratama mengalami kendala dalam hal pengadaan barang, yaitu masih menggunakan pencatatan dan perhitungan secara manual dan tidak ada pencatatan stok barang yang ada pada gudang, selain itu data yang disajikan kurang akurat karena data hilang atau terselip akibat human error.

Dari permasalahan tersebut penulis mengusulkan untuk dibuatkan sebuah sistem untuk membantu menyelesaikan permasalah yang terjadi pada PT.Saka Jagad Pratama.

\section{KAJIAN PUSTAKA DAN LANDASAN TEORI}

\section{Definisi Sistem Informasi}

Sistem informasi adalah suatu sistem di dalam suatu organisasi yang mempertemukan kebutuhan pengolahan transaksi harian yang mendukung fungsi operasi organisasi yang bersifat manajerial dengan kegiatan strategi dari suatu organisasi untuk dapat menyediakan laporan-laporan yang diperlukan oleh pihak luar tertentu(Sutabri. 2012).

\section{Definisi Pengadaan barang}

Pengadaan barang dan jasa adalah upaya mendapatkan barang dan jasa yang diinginkan yang dilakukan atas dasar pemikiran yang logis dan sistematis (the system of thought), mengikuti norma dan etika yang berlaku, berdasarkan metode dan proses pengadaan yang baku(Marbun 2010).

\section{Definisi Monitoring}

Menurut Mudjahidin, Monitoring adalah penilaian yang terus menerus terhadap fungsi kegiatan-kegiatan proyek di dalam konteks jadwal-jadwal pelaksanaan dan terhadap penggunaan input-input proyek oleh kelompok sasaran di dalam konteks harapan-harapan rancangan (Ardi 2018).

\section{Definisi Persedian}

Persediaan adalah bahan atau barang yang disimpan untuk digunakan memenuhi kebutuhan tertentu, misalnya digunakan dalam proses produksi atau untuk dijual kembali(Hendriani dkk 2016)

Penelitian sebelumnya yang dilakukan oleh yang berjudul "Rancang Bangun Sistem Informasi Pengadaan Barang Dan Jasa Berbasis Desktop". Sistem ini membantu perusahaan dalam kegiatan operasionalnya sehari-hari dan juga mempermudah karyawan dalam melakukan pekerjaannya sehingga kesalahan-kesalahan atau kendala yang sering terjadi pada saat masih menggunakan sistem manual dapat dihindari atau bahkan dihilangkan sama sekali(Andhra Saputri 2021). Penelitian lain yang dilakukan oleh Vivi Afifah, Dwipo Setyantoro yang berjudul "Perancangan Sistem Pemilihan dan Penetapan Harga dalam Proses Pengadaan Barang dan Jasa Logistik Berbasis Web". Sistem ini menyeleksi vendor dan penetapan harga pada proses pengadaan barang dan jasa 
logistik berbasis web(Afifah and Setyantoro 2021).

\section{METODE}

Metode yang digunakan dalam penelitian ini adalah prototype, dalam pembuatan sistem metode prototype ini tidak dibuat secara utuh sehingga sistem yang dibangun nantinya akan di uji dan diubah sesuai dengan kebutuhan (Anggoro et al. 2021)(Wulandari, Prayoga, et al. 2021).

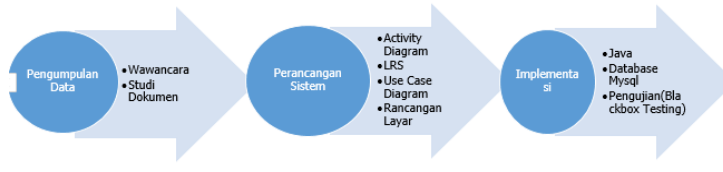

Gambar 1 Langkah - Langkah Penelitian Keterangan:

\section{a. Pengumpulan Data}

Dalam mengumpulkan data penulis melakukan wawancara yang dilakukan untuk mengetahui masalah yang timbul atau dialami langsung oleh yang bersangkutan. Dalam kegiatan ini diajukan pertanyaan lisan dalam usaha melengkapi data yang akan diperoleh disertai dengan mengumpulkan dokumen terkait dengan penelitian yang diambil.

\section{b. Perancangan Sistem}

Perancangan sistem yang dilakukan penulis dilakukan dengan menganalisis dokumen yang di dapat, kemudian dari analisis tersebut diimplementasikan kedalam UML diantaranya Activity Diagram, Use Case Diagram, LRS dan Tampilan Layar.

\section{c. Implementasi Sistem}

Implementasi sistem dalam penelitian ini penulis mendevelop menggunakan JAVA dan database Mysql. untuk pengujian sistem peneliti menggunakan Black-Box Testing.

\section{HASIL DAN PEMBAHASAN}

\section{Activity Diagram}

Berikut ini merupakan beberapa Activity Diagram usulan yang diusulkan pada pada PT. Saka Jagad Pratama :

\section{a. Activity Diagram Pengadaan Barang} Activity Diagram pengadaan barang digambarkan ditunjukkan pada gambar 2 berikut ini::

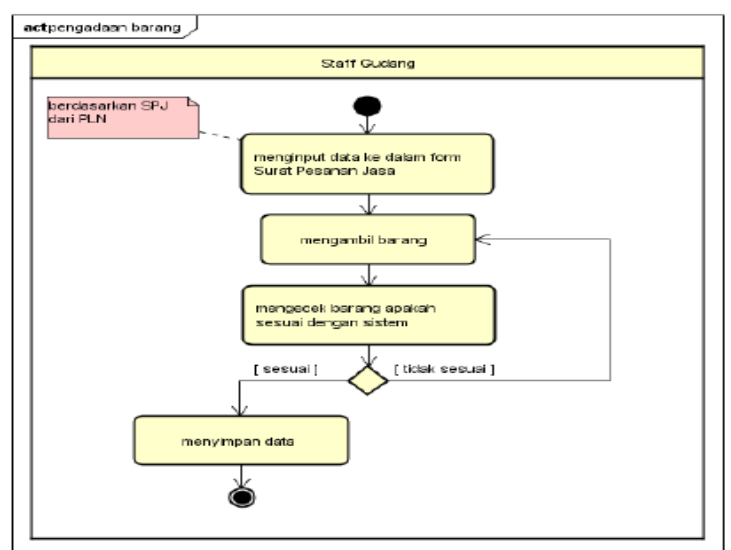

Gambar 2 Activity Diagram Pengadaan Barang

\section{b. Activity Diagram Pekerjaan}

Activity Diagram Pekerjaan ditunjukan pada gambar 3 berikut ini:

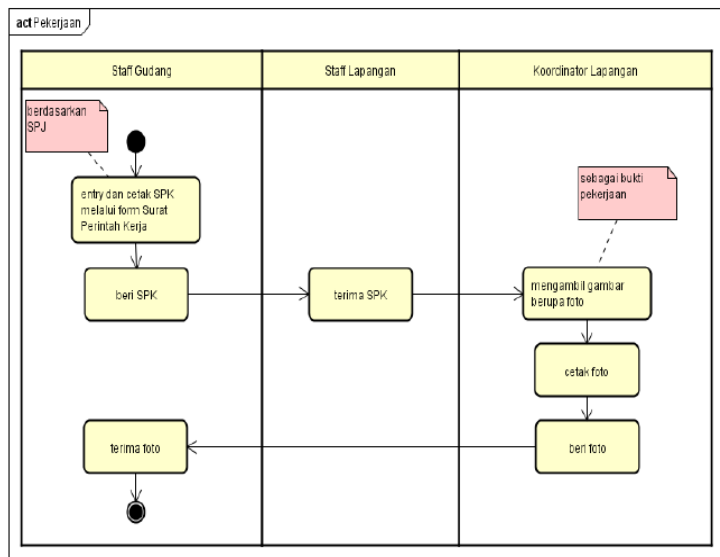

Gambar 3 Activity Diagram Pekerjaan

\section{c. Activity Diagram Pengembalian Barang}

Activity Diagram pengembalian barang ditunjukan pada gambar 4 berikut ini: 


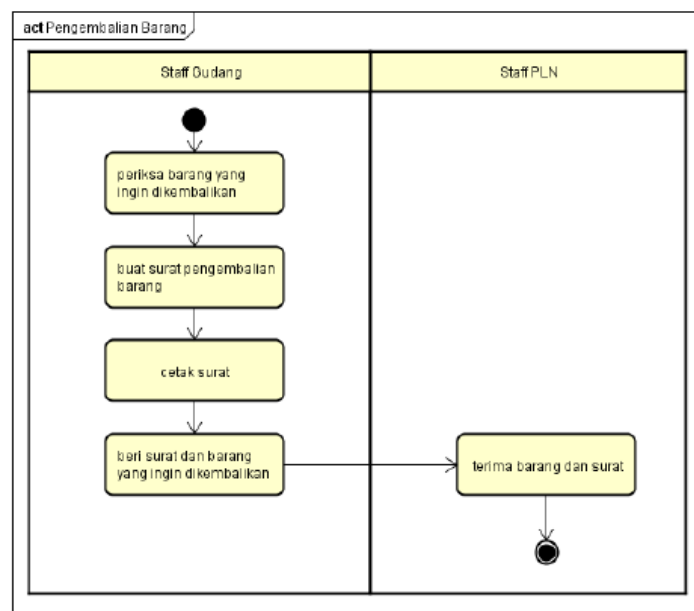

Gambar 4 Activity Diagram pengembalian barang

\section{b. Activity Diagram Laporan}

Activity Diagram laporan ditunjukan pada gambar 5 berikut ini:

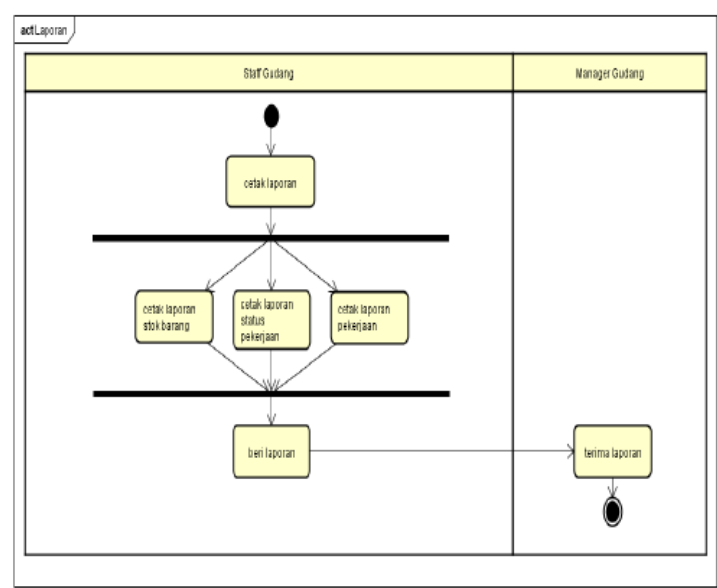

Gambar 5 Activity Diagram Laporan

\section{c. Use Case Diagram}

Use Case Diagram menggambarkan/ menjelaskan siapa pengguna dari sistem yang dibuat dan cara untuk menggunakan sistem tersebut(Sholiq 2010). Use Case diagram transaksi ditunjukan pada Gambar 6.

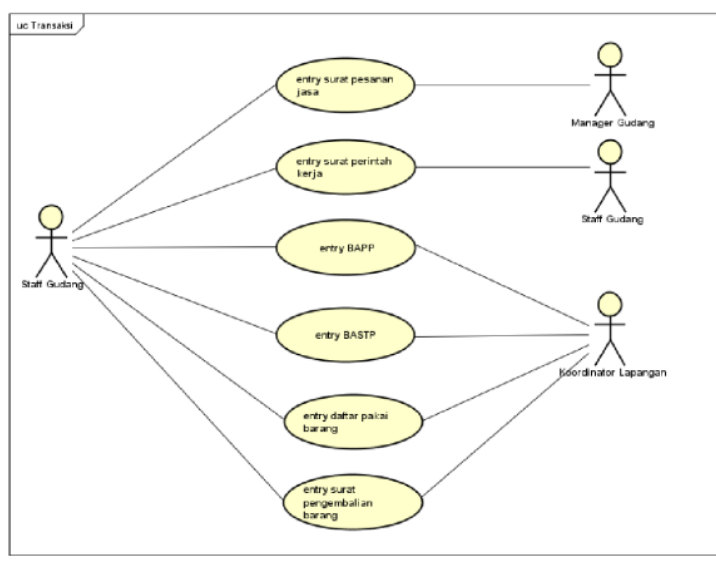

Gambar 6 Use case Diagram Transaksi

\section{Class Diagram}

Class Diagram merupakan hubungan antar kelas dan penjelasan detail tiap-tiap kelas di dalam model desain dari suatu sistem, juga memperlihatkan aturan-aturan dan tanggung jawab entitas yang menentukan perilaku sistem(Hendini 2016). Class Diagram ditunjukan pada gambar 7 .

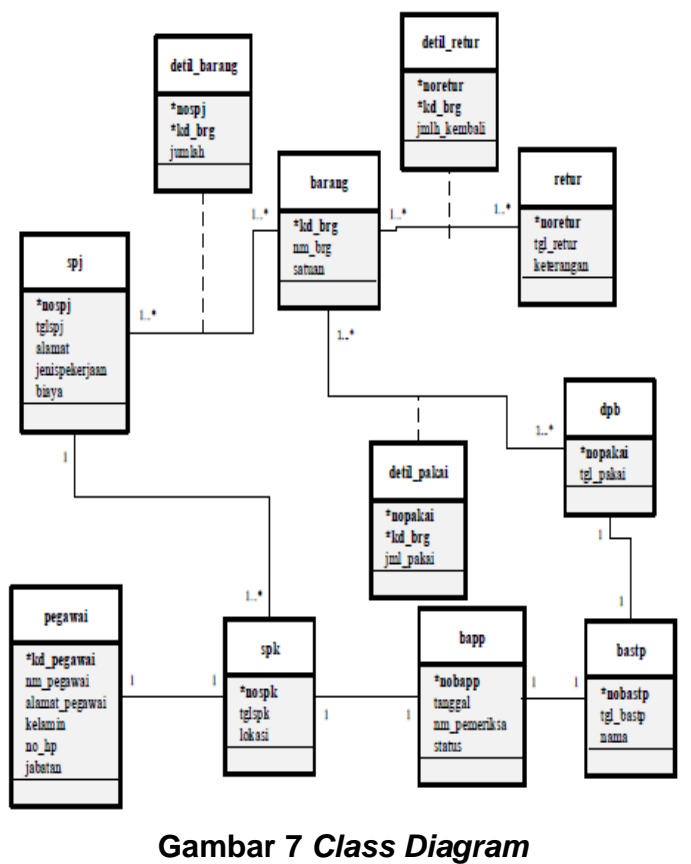

Desain GUI

Berikut ini beberapa struktur tampilan Layar pada PT. Saka Jagad Pratama ditunjukan pada gambar 8, 9, 10. 
a. Rancangan Layar Menu Master

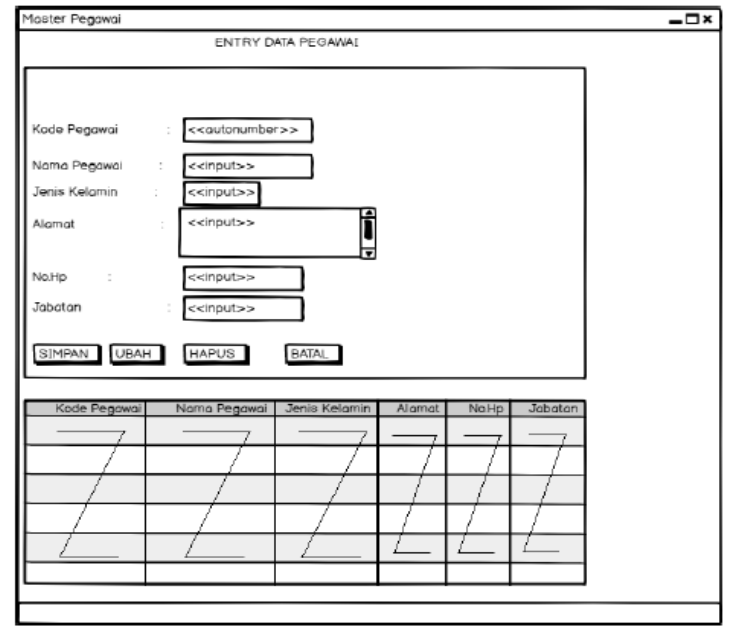

Gambar 8 Rancangan Layar Master Pegawai

b. Rancangan Layar Transaksi

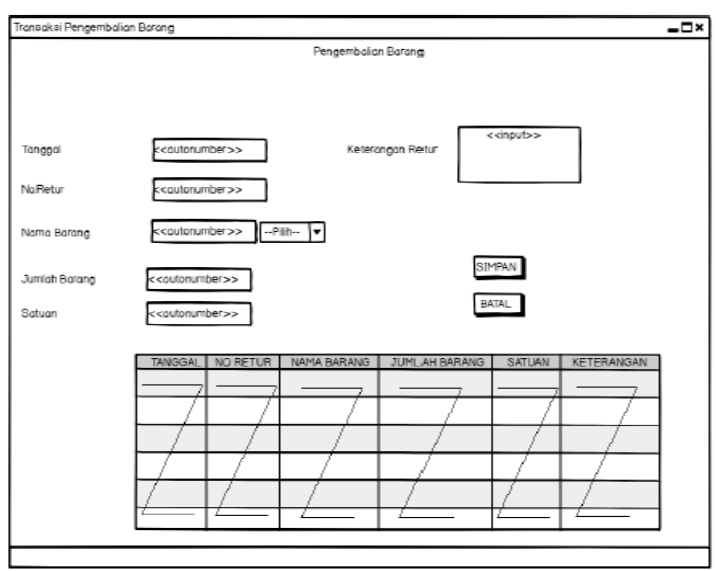

Gambar 9 Rancangan Layar Transaksi Pengembalian Barang

c. Rancangan Layar Laporan

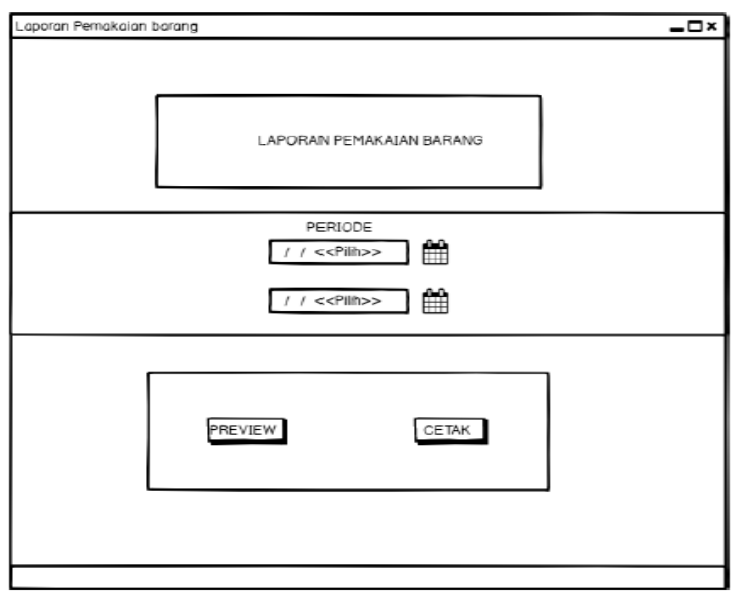

Gambar 10 Rancangan Layar Laporan

Pemakaian Barang

\section{Pengujian}

Pengujian dalam penelitian ini menggunakan metode blackbox testing, yaitu dengan menginputkan ke program sesuai isian yang dibutuhkan, dari inputan tersebut akan dilihat apakah program error atau tidak(Wulandari, Dwi, et al. 2021). Tujuan dilakukan pengujian ini adalah untuk mengetahui keberhasilan dari sistem yang dibangun. Hasil pengujian ditunjukan pada Tabel 1 Berikut ini:

\section{Tabel 1. Pengujian sistem}

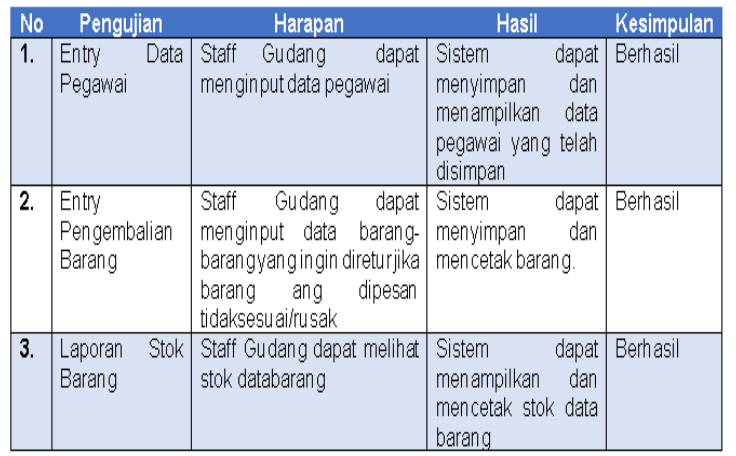

Dari hasil pengujian sistem yang dilakukan, tidak terdapat error pada sistem yang sedang dibangun, sehingga disimpulkan bahwa sistem siap untuk digunakan.

\section{KESIMPULAN Kesimpulan}

Setelah mempelajari permasalahan yang ada dan juga beberapa solusi yang ditawarkan, maka dapat diambil beberapa kesimpulan yaitu:

a. Dengan adanya sistem informasi ini membantu pihak PT.Saka Jagad, dalam memonitoring data stok barang.

b. Dengan dibuatnya sistem informasi ini, membantu PT.Saka Jagad dalam efisiensi waktu pengerjaan laporan.

c. Dengan adanya sistem ini tidak perlu mengkhawatirkan human error karena data yang disajikan akurat. 
a. Perlu adanya pelatihan kepada pegawai atau staf yang akan menggunakan sistem informasi ini, agar mengerti bagaimana cara menggunakan dan perawatan sistem informasi ini.

b. Perlu dilakukan Maintenance secara rutin guna menghindari berbagai kesalahan atau error yang ada pada sistem yang digunakan.

c. Perlu dibuatkan manual book/ Panduan penggunaan sistem, agar mempermudah staf untuk mempelajarinya.

\section{REFERENSI}

Afifah, Vivi, and Dwipo Setyantoro. 2021. "Rancangan Sistem Pemilihan Dan Penetapan Harga Dalam Proses Pengadaan Barang Dan Jasa Logistik Berbasis Web." Jurnal IKRA-ITH INFORMATIKA 5(2): 108-17.

Andharsaputri, Resti Lia. 2021. "Rancang Bangun Sistem Informasi Pengadaan Barang Dan Jasa Berbasis Desktop." Jurnal IImiah Teknologi Informasi Asia 15(1): 1-12.

Anggoro, Dani, Rayyan Budiman, Rhesa Ariesco Febrian, and Yandika Gema Kumara. 2021. "Perancangan Sistem Informasi Penjualan Berbasis Web Pada Lookass Lookiss Art Work Garage." IDEALIS 4: 31-36.

Ardi, Elgusti. 2018. "Rancang Bangun Sistem Informasi Perawatan Dan Pengadaan Barang Alat Suku Cadang mesin Produksi." Universitas Islam Negeri Sultan Syarif Kasim Riau.

Fajarita, Lusi et al. 2018. "Penerapan Forecasting Stright Line Method Dalam Pengadaan Stok Barang Mendatang." : 310-17.
Hendini, Ade. 2016. "Pemodelan Uml Sistem Informasi Monitoring Penjualan Dan Stokbarang (Studi Kasus: Distro Zhezha Pontianak)." Jurnal Khatulistiwa Informatika IV, No 2(2): 107-16.

Hendriani dkk. 2016. "Sistem Peramalan Persediaan Obat Dengan Metode Weight Moving Average Dan Reorder Point (Studi Kasus: Puskesmas Soropia)." semanTIK 2(2): 207-14.

Marbun, Rocky. 2010. Tanya Jawab Seputar Pengadaan Barang/Jasa Pemerintahan. Jakarta: Visi Media.

Sholiq. 2010. Analisa Dan Perancangan Berorientasi Objek Title. Yogyakarta: Graha IImu.

Sutabri., Tata. 2012. Analisis Sistem Informasi. Yogyakarta: Andi.

Wulandari. 2020. "Implementasi Sistem Peramalan Persediaan Barang Menggunakan Metode Moving Average." Jurnal Media Informatika Budidarma 4: 707-14.

Wulandari, Pandu Dwi, Putra Nugroho, and Farhan Ramadhan. 2021. "Rancangan Sistem Informasi Penyewaan Bus Dengan Pendekatan Electronic Customer Relationship." INDONESIA JOURNAL INFORMATION SYSTEM (IDEALIS) 4: 110.

Wulandari, Indiarto Prayoga, Bayu Hasmoro Putro, and Resita Sri Wahyuni. 2021. "Rancangan Aplikasi Penjualan Hewan Qurban Dan Aqiqah Pada Raisha Farm Guna Memperluas Area Penjualan." IDEALIS 4: 215-22. 